\section{The advantages of an incubator} For bioentrepreneurs looking for a home for their startups, there are very obvious advantages of incubators: they permit company founders to conserve cash and accelerate the commercialization of their technology by providing, if necessary, interim management and access to professional advisers (e.g., legal and financial specialists and patent agents) and shared but secure laboratory facilities.

In addition, for a university spinout, incubators help to shift the startup's culture from an academic perspective to an entrepreneurial one. Incubator staff can help with branding the company, increasing the confidence of investors that they are dealing with a commercial entity separatefrom a university. A successful biotechnology incubator is unlikely to bejust a supplier of cheap real estate with laboratory resources in isolation from a technology pipeline. The incubator should ensure that a company's first steps makethelater ones easier.

In summary, a good incubator should help to turn ideas into a commercial reality.

\section{The future for incubation}

The initial success of $M$ anchester Innovation has encouraged us to plan a second incubator, and the university has made land available adjacent to the present building. At this stage, definite funding has not been pledged, but wehope to beableto construct a building large enough to house future biotechnology startups and to offer some core technology facilities and a lecture theatre.

Is the pipeline of new biotechnology startups sufficiently robust to justify our optimism? Interesting results have come from asking industrialists to say which of their products could not have been developed (without substantial delay) in the absence of recent academic research ${ }^{3}$. Within the US health care and pharmaceuticals industry, $31 \%$ of all new drugs and medical products launched during 1986-1994 were said to fall into this category.

There is intriguing evidence to suggest that universities may bean even more important source of new drugs in the future. The decrease in the number of new chemical entities reaching the market in recent years is of concern to the pharmaceutical industry. While the number of mergers and acquisitions in the pharmaceutical industry has increased, so has the number of companies involved in pharmaceutical research and development. According to the Scrip review of 2001 (ref. 4), the number of small companies is increasing: Between 1997 and January 2002, the number of companies with only one or two projects increased by almost 200.
Themajority of these companies will have originated from universities

Recently Sir Richard Sykes, formerly nonexecutivechairman of GlaxoSmithKline and now rector of Imperial College (London), reinforced the need to provide the "necessary environment" for growth of companies from academia. There is a compelling argument that part of the "necessary environment" mentioned by Sir Richard should includea properly managed incubator to promote entrepreneurial activity.

It is, of course, difficult to provethat incubators can assist university researchers to commercialize their ideas effectively, but certainly the $M$ anchester experience is encouraging. The main beneficiaries of advances in biotechnology - the pharmaceutical industry-are increasingly struggling for innovativepipelines. Sustainablegrowth in many areas including health careis likely to rely increasingly on interdependent networks and alliances rather than scientific self-sufficiency.

Continuing success will be dependent on new mindsets and capabilities creating value from intellectual property. The contribution of emerging "can-do" locations such as the $M$ anchester Incubator should help to sustain the competitive edge in the market applications of biotechnology.

1. Salter A.J. and Martin B.R. The economic benefits of publicly funded research: a critical review. Research Policy 30, 509-532 (2001).

2. Biotechnology Clusters (August 1999) report by a team led by Lord Sainsbury, Minister for Science defined clusters as "geographic concentrations of interconnected companies, specialised suppliers, service providers, firms in related industries and associated institutions e.g., universities."

3. Mansfield, E. Academic Research and Industrial Innovation: An update of empirical findings. Research Policy 26 773-776 (1998)

4. R\&D revolution remains just around the corner. Scrip February, 72-73 (2002).

\title{
Incubation without walls
}

No bricks, no mortar ... but lots of encouragement, introductions, good advice, and minimum conflicts of interest at the Massachusetts Institute of Technology, say Thomas Ittelson and Lita Nelsen.

harles M . Vest, the president of the $M$ assachusetts Institute of Technology (MIT), once said, "... the primary goal of university licensing and associated offices and policies should be to move technology rapidly to industry [for development]." And indeed, the M IT's Technology Licensing Office (the "TLO") has the responsibility of placing inventions generated at M IT into the commercial sector where they can be best exploited for the public good.

This article describes the TLO's "virtual incubator" approach to starting businesses from M IT technology-a "non-bricks-andmortar" method of fostering entrepreneurial activities within the MIT community.

\section{Spotting the startup}

M ost often, inventions at the Institute are incremental improvements (sometimes

Thomas Ittelson is director of the intellectual property office, Whitehead Institute for Biomedical Research, Cambridge, M A (ittelson@mit.edu), and Lita N elsen is director of the technology licensing office, $M$ assachusetts Institute of Technology, (lita@mit.edu). important) to existing technologies or potential product extensions. In general, most incremental inventions are suitable for licensing to existing businesses in the field. However, around onein ten inventions arriving at the TLO has the technical and market potential to support an entirely new enterprise.

Each year, M IT research (and subsequent patents) form the technological basis for 25 or so such entrepreneurial business startups. O ver the past 15 years, the TLO has facilitated the formation of more than 250 such businesses, including such leaders within the biotechnology sector as A riad Pharmaceuticals, Cubist Pharmaceuticals, ImmuLogic Pharmaceuticals, StressGen Biopharmaceuticals, and Praecis Pharmaceuticals.

So, what makes a good startup opportunity? Positive indicators include very earlystage research, a technology that has several potential applications, no existing companies dominating the field, and an inventor who wants to participate actively in his or her invention's commercialization. We find that embryonic technologies with multiple new markets are often best exploited by focused and dedicated entrepreneurs funded 
by venture capitalists who understand technical and business risk and reward.

M IT startup opportunities usually have no business plan or even the beginnings of a management team. Often theinvention has not yet been "reduced to practice" (i.e., proven to work), but the underpinning technology can have broad promise and can be potentially enabling in an important commercial arena. Thelnstitute scientist-inventor can bea real visionary and technology champion. Then, if business conditions are favorable - a large potential market and large potential return with no current dominating competition- the TLO will try its best to fan entrepreneurial fires.

\section{MIT's virtual incubator}

TheTLO uses a "virtual incubator" model to start up businesses based on Institute technology. We do not offer "physical" support, such as space and seed financing, and we do not write business plans, although we are happy to critique them. However, we do offer lots of encouragement, and provide matchmaking services with source of funding and potential management talent. Also, the TLO will pay for patent applications to protect the technology while the fledging (and unfunded) business is setting itself up. When thetime comes, our licensing procedures are straightforward, with negotiation, commitment to proceed, and creation and signing of the license agreement all carried out within the TLO.

The TLO aims to be a conduit to, and not a gate between, venture capital ists and the faculty. We meet regularly with venture capitalists to discuss new technologies and ongoing research at the Institute that may be appropriate for a startup venture. We encourage venture capitalists to meet independently with the faculty, and we will make introductions and counsel faculty on the goals and objectives of venture capitalists and how best to interact with them. In an environment where it can be hard for entrepreneurs to get their business plans read (or even tel ephone calls returned), an introduction to a venture capital company can be invaluable. The TLO's success has gained the respect of the venture capital community, which now looks to us as a source of future opportunities. However, we will not represent a faculty member in negotiating his or her personal rolein a proposed startup venture, regarding any such representation as a potential conflict with the TLO's primary charter as a "shepherd" of the technology.

Licensing staff at the TLO are experienced negotiators who can navigate the shoals of venture capitalists' demands, inventor ego, not-for-profit policy, and governmental regulations. M ost of them have many years of industrial experience (the current average is 28 years), often in business development jobs and in smaller, entrepreneurial companies.

\section{Recipe for success}

Why have we succeeded? First and foremost, MIT has a wealth of good technology - technology that can beworld-class and that, while very embryonic and basic, often has great potential commercial value.

Second, the M IT environment is very supportive to startup ventures. At M IT, industrial careers are respected (even in the biological sciences), and entrepreneurship is thegoal of many on campus. Importantly, success does beget success. Past successful M IT startup ventures encourage faculty and students to taketheplunge themselves and providea group of very visible and accessible role models-a real cheerleading group. Further, entrepreneurship garners enthusiastic support from senior Institute administrators who understand their mission.

Third, although the TLO can hardly take the credit, theBoston/Cambridge area is a great place to start a business. M ore than $80 \%$ of M IT startups locate in eastern

$M$ assachusetts. Facilities are available and friendly landlordsare ready to build out (and finance) spaceto the exact requirements of the startup. Thelarge academic community provides a large pool of talented young scientists to staff research programs.

\section{Minimizing conflict}

The overriding purpose of the Institute and its faculty is the discovery and dissemination of knowledge. Commercial application of that knowledge is left to those outside the open and "not-for-profit" strictures under which the Institute operates. With so much entrepreneurial activity at the Institute, we have evolved clear policies to draw the line between Institute-encouraged entrepreneurism and misplaced forprofit commercial activity.

Our goal at the TLO is adequate" conflict minimization". Weare not trying to impede or limit the entrepreneurial activities of the faculty, but rather to provide faculty and students with guidance regarding what is collectively regarded as appropriatebehavior at the interface between knowledgefor its own sake and commerce. But ultimately, and regardless of strictures, theindividual faculty members are responsiblefor themselves.

Three basic principles guide M IT's conflict-of-interest policiesfor technology transfer, and these same principles also apply to Institute startup activities.
- Technology transfer and entrepreneurial activities areby-products (not the purpose) of the academic mission of education, basic (discovery) research, and dissemination of knowledge.

- Technology transfer activities must not deflect or distort this core mission.

-When conflicts of mission arise, theacademic mission always takes precedence.

M IT's business startup conflict-of-interest rules were formulated during the late $1980 \mathrm{~s}$ and remain essentially unchanged 250 startups later. We regard them as a conservative attempt to erect an appropriate "Chinese Wall" between academia and the startup company, allowing both to prosper independently. These well-publicized rules are listed here: - There must be no incubation of thecompany within MIT once it has been formed.

- Faculty members may consult and beboard members, but may not beline officers of the company.

- Faculty are required to report all outside consulting activities including activities with startups.

- Faculty members may not negotiate terms of thelicense with MIT.

- No sponsored research will be accepted from the company if thefaculty founder holds equity in the startup.

- No confidentiality of M IT research results is permitted; everything is published.

- Only patents and copyrights can belicensed (no exclusivelicenses to "know how" or trade secrets).

In addition, before starting up a company the faculty founders must sign a "conflict avoidance statement", promising not to accept research support from the company, not to suppress for the company's ben efit the dissemination of research results developed at $\mathrm{MIT}$, and not to use students on any company projects (that is, current students may not be employed by the startup company).

All the financial dealings between thenew company and the Institute are kept at arms' length. M IT will not invest in early funding rounds and takes no board seat. Any equity received by the Institute from the startup at its inception is managed by the M IT treasurer, not by the TLO. Importantly, the company receives no rights in future research in the field of the license.

These clear policies, well thought out and consistently applied, are designed to facilitate startups. The simplicity, strictness, and "no exceptions" rules for keeping M IT and its startups separate actually help keep things moving, because negotiations do not get bogged down while committees ponder over exceptions and risks. 